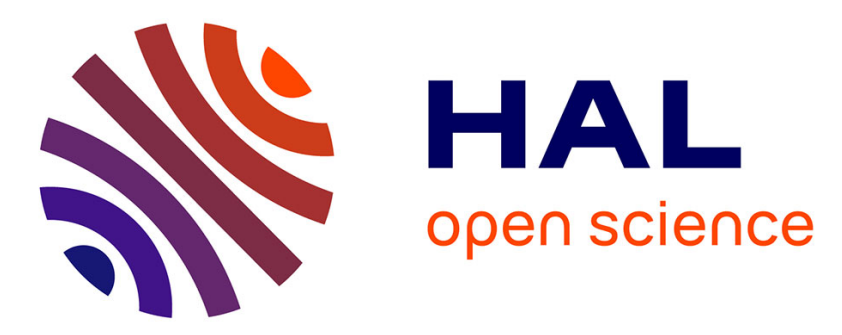

\title{
Tobin tax and trading volume tightening: a reassessment
}

Olivier Damette, Stéphane Goutte

\section{To cite this version:}

Olivier Damette, Stéphane Goutte. Tobin tax and trading volume tightening: a reassessment. 2014. hal-01203841v1

\author{
HAL Id: hal-01203841 \\ https://shs.hal.science/hal-01203841v1 \\ Preprint submitted on 10 Jan 2014 (v1), last revised 7 Apr 2023 (v2)
}

HAL is a multi-disciplinary open access archive for the deposit and dissemination of scientific research documents, whether they are published or not. The documents may come from teaching and research institutions in France or abroad, or from public or private research centers
L'archive ouverte pluridisciplinaire HAL, est destinée au dépôt et à la diffusion de documents scientifiques de niveau recherche, publiés ou non, émanant des établissements d'enseignement et de recherche français ou étrangers, des laboratoires publics ou privés.

\section{(c)(1)}

Distributed under a Creative Commons Attribution| 4.0 International License 


\section{Les Cahiers du LED}

Tobin tax and trading volume tightening : a reassessment.

Olivier DAMETTE (Université de Lorraine, BETA) et Stéphane GOUTTE (Université Paris 8, LED)

Document de travail $\mathrm{N}^{\circ} 54$

Janvier 2014

\section{LED}

Laboratoire d'Économie Dionysien

Université Paris 8

EA 3391 


\title{
Tobin tax and trading volume tightening: a reassessment
}

\author{
Olivier DAMETTE *AND Stéphane GOUTTE ${ }^{\dagger}$
}

January 9, 2014

\begin{abstract}
This article extends the previous literature on the Tobin tax and financial transaction tax. We investigate the linkages between trading volumes and transaction costs using both a linear and a nonlinear methodology. In stark contrast with previous studies, we consider the possibility that our model may exhibit threshold effects or regime dependency by estimating a Markov Switching (MS) model. This paper is the first contribution to specify the trading volume of the Forex through different (low and high volatility) regimes. Our empirical investigation looks at the EUR/USD currency market. Our results show evidence of nonlinear patterns for trading volumes and transaction costs on the Forex. The Tobin tax would not have a monotonic impact on trading activity across market conditions. However, the change in elasticity between low and high volatility regimes is slight (-0.17 versus -0.21$)$. We may suggest that the low-variance regime might be the fundamentalist regime and the highvariance regime (lower Tobin tax elasticity) might be the chartist regime. This study is a first step towards understanding which categories of agents dominate the market under the various market regimes and how they would react to the introduction of a tax. This means our results are consistent with Tobin's underlying thinking $(1974,1978,1996)$. Since a tax would penalize chartists more than fundamentalists, it could reduce exchange rate volatility.
\end{abstract}

Keywords: Tobin tax, trading volume, Forex, transaction costs, global financial crisis, Markov switching.

JEL Classification (2010): E44, F31, C22

\footnotetext{
*BETA-CNRS - Université de Lorraine, 13 place Carnot, 54035 Nancy Cedex, France

${ }^{\dagger}$ LED - Université Paris 8, 2 rue de la Liberté, 93526 Saint-Denis Cedex, France.

Email: stephane.goutte@univ-paris8.fr and olivier.damette@univ-lorraine.fr.
} 


\section{Introduction}

Now that other global taxes (carbon and environmental taxes, airline tickets, etc.) have been implemented, the emergence of the subprime crisis and the recent sovereign debt crisis have led to renewed interest in a financial transaction tax (FTT). In the last two years, the so-called Tobin tax project has gained support among European governments. Recently (22 January 2013), the European Commission formally proposed introducing a tax on financial transactions across 11 EU countries by January 2014: Austria, Belgium, Estonia, France, Germany, Greece, Italy, Portugal, Slovakia, Slovenia and Spain. However, this proposal is under pressure. This is not surprising because the Tobin tax is an emotive issue as recently pointed out in a survey by McCulloch and Pacillo (2011). Its supporters claim that a Tobin tax could generate very high revenues and at the same time stabilise financial markets by reducing exchange rate volatility. Its opponents argue that a Tobin tax might prove counterproductive by increasing exchange rate volatility. There are other polemical questions about political feasibility and potential revenues.

First suggested in 1972, the Tobin tax project has had a chaotic existence. When James Tobin first suggested putting "some sand in the wheels of international finance" by imposing a tax on all foreign exchange transactions during the Janeway Lectures at Princeton [1972] the "idea fell like a stone in a deep well" (1978, p. 490). Tobin explained that a tax would reduce volatility by discouraging short-term transactions (thereby curbing destabilising speculative trading) to a greater extent than long-term transactions (and investments) and thus crowding out speculators and noise traders from foreign exchange markets (Forex hereafter) in favour of fundamentalists and long-term investors. However, this argument has been strongly challenged by proponents and opponents of the tax alike.

This emotive feature of the Tobin tax debate may explain why there are few academic studies of the topic. Since the major contribution from Haq Kaul and Grunberg (1996), only a handful of significant contributions have emerged: Mende and Menkhoff (2003), Ehrestein et al. (2005), Westerhoof and Dieci (2006), Shi and Xu (2010), Hanke et al. (2010). To the best of our knowledge, academic studies of the seminal tax project on currency transactions as proposed by Tobin (1974)are even scarcer. Above all, there is a dearth of empirical studies into the impact of the Tobin tax and especially its impact on trading volumes ${ }^{1}$. In 2002, the OECD pointed to the "lack of empirical evidence about trading volumes with respect to the spreads". The focus of our paper is to fill the gap in this literature by estimating how the Forex trading volume would decrease if a Tobin tax were introduced. Since no Tobin tax has yet been implemented, it is apprehended as an increase in spreads or in general as an increase in transaction costs.

\footnotetext{
${ }^{1}$ There are however two empirical studies of the effect of a Tobin tax on volatility: Aliber et al. (2003) and Lanne and Vesala (2010).
} 
Here we focus on the "true" Tobin tax and not a financial transaction tax with which it is commonly confused. Nobel prize winner James Tobin said his tax would be levied on currency transactions alone, making it a securities transaction tax imposed specifically on foreign exchange transactions (spot and possibly derivatives transactions): every conversion of domestic currency into any foreign currency would be taxed at a low rate (1\%). Other transaction taxes (stocks, sovereign bonds, etc.) were ignored.

Though previous studies have calculated financial transaction tax elasticities on equity markets (see section 2), little work has been done on the Forex. We therefore need to assess currency transaction tax elasticity, not equity taxes alone. Furthermore, the foreign exchange market is the largest tax base that would be concerned by the financial tax project.

Calculating "Tobin tax elasticity" enables us to better understand the effects of such a tax on exchange rate volatility. Since the volume of transactions and the number of traders entering the foreign exchange market are correlated with price efficiency, transaction costs, trading volumes and volatility are all closely interrelated. A clearer understanding of the fall in trading volumes engendered by a Tobin tax would provide insight into how the policy impacts efficiency and volatility. In addition, having some idea of the elasticity of the trading volume to the tax would enable us to better estimate the potential revenues from the tax. Previous attempts to estimate those potential revenues were compelled to assume some a priori elasticity of the tax base to the Tobin tax. A robust measure of this elasticity will improve forecasts of the potential revenues from a Tobin tax.

Our empirical findings include some interesting new results that extend the previous literature on the Tobin tax and financial transaction tax and enhance our understanding of Forex microstructure. We investigate the linkages between trading volumes and transaction costs using both a linear and a nonlinear methodology. In stark contrast with previous studies, we consider the possibility that our model may exhibit threshold effects or regime dependency. More specifically, we estimate a Markov Switching (MS) model to test the hypothesis of regime switching. This paper is the first contribution to specify the trading volume of the Forex through different (low and high volatility) regimes. Our empirical investigation looks at the EUR/USD currency market, that is, the most traded currency pair on the foreign exchange market. Our results show evidence of asymmetrical and nonlinear patterns for trading volumes and transaction costs on the Forex. The Tobin tax would not have a monotonic impact on trading activity across market conditions. However, the change in elasticity between low and high volatility regimes is slight $(-0.17$ versus -0.21$)$.

The paper is structured as follows. Section 2 sets out the econometric framework and section 3 presents the dataset and the descriptive analysis. Markov switching analysis is outlined in section 4. The discussion appears in section 5 . 


\section{Review of the Literature and the Tobin Tax Elasticity Frame- work}

A number of studies have already calculated financial transaction tax elasticities. However, most of them relate to the equity market. Mean values of those elasticities (see McCulloch and Pacillo (2011) for a literature review) lie between 0.58 or 0.8 (for the Shanghai Stock Exchange Market, see Zhang (NA) and Schwert and Seguin (1993)) and 1.275 (Jackson and O'Donell (1985) for the UK stock market). Recently, Baltagi et al. (2006) have found unit elasticity of the Chinese stock market volume to transaction costs.

Our study, as said, focuses on the Forex market. Studies of this market may be scarce because data on Forex trading activity and prices are difficult to collect. Indeed, the foreign exchange market is decentralised and opaque. To circumvent this problem, Aliber et al. (2003) used futures data as a proxy with which to study the effect of transaction costs on volatility. Futures data are traded on a centralized market and are readily available. However, the turnover of foreign exchange futures is only $3 \%$ of total Forex turnover and is less liquid.

Recently, Bismans and Damette (2008) estimated the currency transaction tax elasticity using an original data set from Reuters Dealing 3000 for four currency pairs: US dollar against the euro, yen, pound sterling and Canadian dollar. All estimates are for two single days in November 2004 (one-minute data, that is 1600 observations). Since the series (trading volume, spreads, etc.) are integrated of in the same order, they used cointegration techniques to assess elasticity. Time series estimates for the Euro-Dollar currency pair reveal an elasticity of -0.61 . That is, a doubling of transaction costs would cause volumes to fall by $61 \%$. To account for cross-market effects (traders react the same way for different markets and so different currency pairs), they also provide SURE estimates (-0.33 for the Euro/Dollar currency pair). Finally, they estimate an overall elasticity on all the markets using Panel DOLS (-0.61) which is very similar to time series estimates. Overall, these estimates are lower than some of the ad hoc elasticities used in studies forecasting the potential revenues from a Tobin tax: Felix and Sau (1996) used a value range from -0.75 to -1.5 whereas the French Ministry of the Economy (2000) and the Belgian Ministry of Finance (2001) assumed values of -0.5 to -1.5. In addition, these Forex elasticities are lower than equity market elasticities.

However, as underlined by Schmidt and Bhushan (2011), the work of Bismans and Damette (2008) is based on a two-day microstructure dataset. Thus, elasticities are highly likely to change with market circumstances and structural features, making it a tenuous exercise to characterise these results as a robust feature of the markets. Schmidt (2008) estimated the elasticity in

the dollar/yen market for the period 1986-2006. Using a simultaneous equations time series 
regression model to take into account potential endogeneity between trading volume and bidask spreads which he used as a proxy for transaction costs, he arrived at an elasticity of -0.43 .

In this paper, we directly assess the Tobin tax elasticity by estimating the relationship between trading volumes and transaction costs by controlling for the effect of volatility on trading volume. Volatility does influence trading volume (see, for instance, Demos and Goodhart (1996)), especially via the Mixture Distribution Hypothesis channel. Both volume and spread are expressed in logarithmic form to directly obtain the coefficient as an elasticity. Consequently, it is possible to directly read the impact of a Tobin tax - equivalent to a rise in transaction costs - on the trading volume through the estimated elasticity.

Initially, we estimate a linear autoregressive model of the following form:

$$
\log (\text { volume })_{t}=\beta_{1}+\beta_{2, X_{t}} \log (T C)_{t}+\beta_{3} \log (\text { volume })_{t-k}+\beta_{4, X_{t}} \log (\text { volatility })_{t}+\varepsilon_{1, t, X_{t}} .
$$

TC denotes transaction costs, volume refers to trading volume and volatility to exchange rate volatility, $k$ is the lag length and $t$ denotes the time dimension $(t=1, \ldots 600)$. In this model, we assume transaction costs are weakly exogeneous. To check the robustness of this single equation model, we also specify a simultaneous equations model to take into account the potential endogeneity of the transaction costs (see next section).

Then, we test the linearity properties of the previous model by computing rolling regressions. Given the nonlinearity dynamics of the trading volume, we then estimate Markov Switching (MS) models. The underlying idea is that trading volume may be more and less reduced in function of market volatility.

\section{Data and Preliminary Analysis}

\subsection{Data and Descriptive Analysis}

To assess the Tobin tax elasticity, we use exchange rate quotations and trading volume series for the Euro-Dollar currency pair. We collect an intradaily data set from Olsen Financial Technologies ranging from 15 September 2008 to 31 December 2010. In other words, our data set includes the period from the bankruptcy of Lehman Brothers to the end of the year 2010. This data set (600 observations) is therefore bigger than in most previous empirical studies of the Tobin tax. We expect to capture periods of stress alternating with periods of relative calm: for instance, the starting point of the sample is related to the onset of the subprime crisis, that is 
a period of stress, whereas spring 2009 saw a slow down on the foreign exchange market, with smaller trading volumes and low transaction costs. In addition, because our data set is very recent it is likely to capture some recent features of the workings of the foreign exchange market.

Three variables are needed to assess elasticity in our empirical analysis: trading volume, transaction costs and volatility. Since the foreign exchange market is decentralised, the volume of transactions is not readily available. Proxies are thus needed (see Hartmann (1998) for a survey). In this paper, we use the quoting frequency (Reuters tick by tick data) to proxy the trading volume. Even though tick data have some shortcomings (for instance, quoted spreads are usually larger than traded spreads), these data really matter only at very high frequencies(Demos and Goodhart (1996)). We use daily volumes obtained by summing the 5-min intradaily volumes of our data set. We turn next to the transaction costs variable. Absolute or relative spreads (Bid-Ask or $\log (\mathrm{Bid})-\log ($ Ask $)$ ) are usually used to proxy transaction costs on the Forex ${ }^{2}$. Bismans and Damette (2008), Schmidt (2008) and Damette (2013) also used spreads to empirically evaluate the Tobin tax effects on volume and volatility. In contrast, we use here a more accurate definition in line with Aliber et al. (2003): $T C=\frac{A_{\text {med }}-B_{\text {med }}}{A_{\text {med }}+B_{\text {med }}}$.

Some descriptive statistics are outlined to explore the data set at hand. Summary statistics of our log-range data (logarithm of the trading volume and transaction costs) are reported in table 1. The skewness and kurtosis coefficient values show that our time series are not normally distributed (unconditionally, see also the Jarque-Bera test). This may suggest that nonlinear econometrics is needed to capture the dynamics of our series.

Moreover, the transaction costs and trading volumes are displayed in figures 1 and 2 respectively. They exhibit an overall decreasing dynamics, especially from the first to the 400th observation (corresponding to the period from September 2008 to April 2010). Between April and September 2010 (420th to 520th observation), the dynamics of transaction costs is relatively stable. A sharp decline occurs after September 2010 i.e. in the last part of the sample.

Daily volume dynamics surges at the beginning of the sample. Transaction costs for the same period are relatively stable. Historically, this period corresponds to "Black October" and November 2008; the first wave of the subprime crisis. Melvin and Taylor (2009) point out that the Forex was then in crisis: de-leveraging was unlike anything that had been witnessed before, volatility soared and spreads were $400 \%$ above normal. In this kind of regime, both trading volume and volatility are simultaneously high and the market is dominated by herd behaviours and psychological effects (Park (2010, 2011)) which further increase the trading volume (see figure 1). This increase in trading volume can be viewed as the result of an increase in speculative and chartist behaviours and noise traders transactions. For instance, in the model

\footnotetext{
${ }^{2}$ See Hartmann (1999) for an empirical paper about the determinants of Forex spreads.
} 
Figure 1: Trading volume dynamics

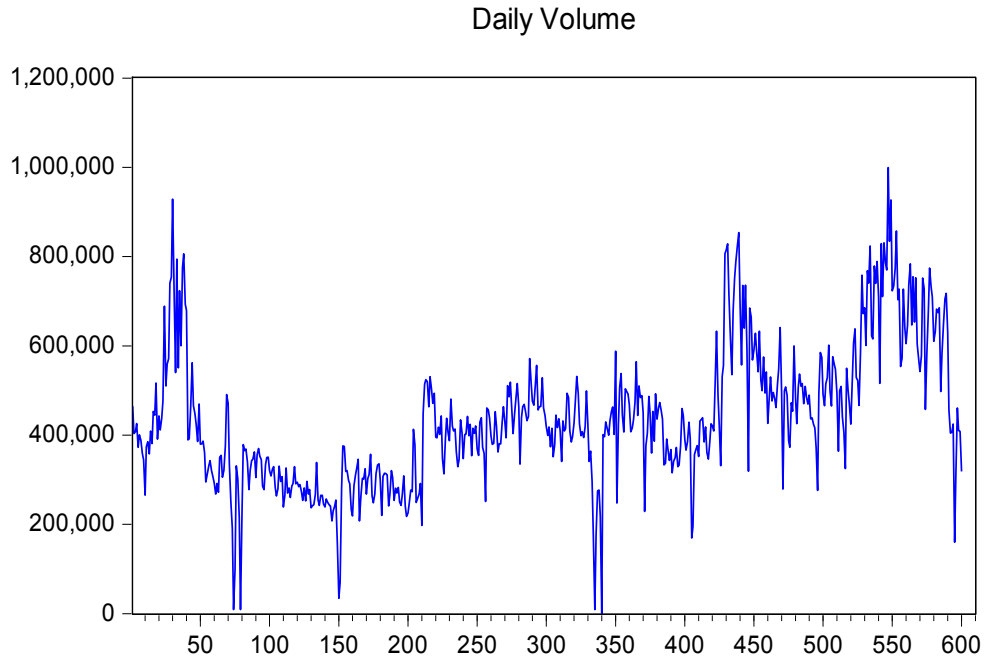



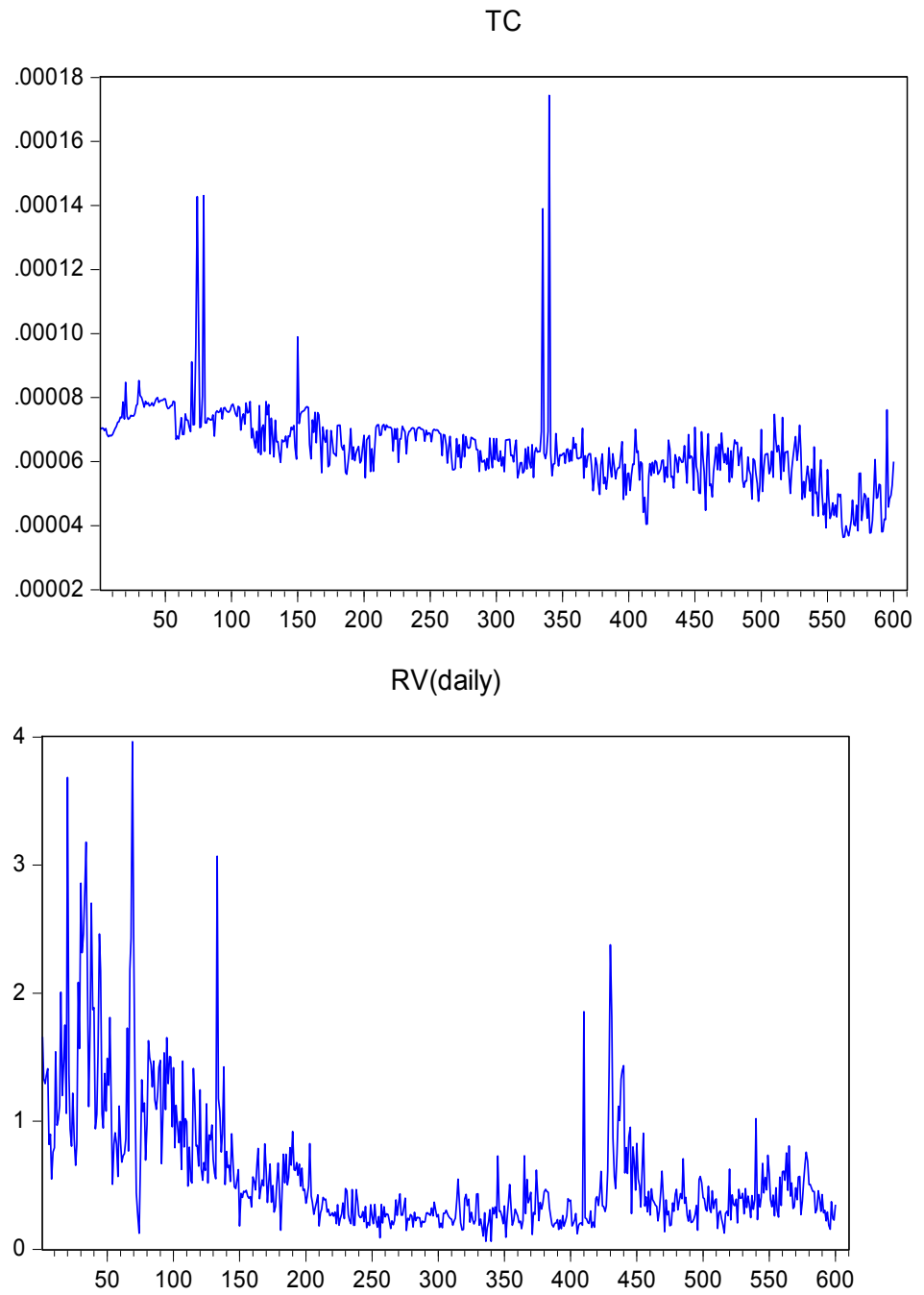
of Jeanne and Rose (2002), the overall exchange rate volatility is a nonlinear function of the relative number of noise traders on the market. Noise traders have two counter-acting roles: they are risk-sharing at low volume and liquidity levels but they create risk when liquidity is high. Hence, we may suggest that the surge in trading volume at the beginning of the crisis is the outcome of noise tradersâŢ $\breve{S}$ risk-sharing behaviours. The ensuing decline in the trading volumes from January 2009 to April 2010 (80th to 150th observations) is indicative of the second role of the noise traders, who have created more risk than they have absorbed. The period of active trading can also be analysed in line with Melvin and Taylor (2009) as a faster hot-potato process in response to the increasing risk.

For the remainder of the sample, overall daily trading volumes rise while transaction costs fall. Two exceptions are noticeable: April to September 2010 (420th to 520th observations) and November to December 2010 (560th observation to the end of the sample). Descriptive results are thus in line with an expected negative elasticity of trading volumes to transaction costs. In compliance with the Forex microstructure theory, decreasing (resp. increasing) transaction costs lead to increasing (resp. decreasing) trading volumes.

Table 1: Descriptive Statistics

$\begin{array}{cccc}\text { Statistics } & \text { Log Realized Volatility } & \text { Transaction Costs } & \text { Log Trading Volume } \\ \text { Mean } & -0.80017 & 0.06398 & 12.90361 \\ \text { Median } & -0.90571 & 0.06357 & 12.94402 \\ \text { Minimum } & -2.79102 & 0.03634 & 6.36303 \\ \text { Maximum } & 1.37736 & 0.17438 & 13.81501 \\ \text { Variance } & 0.48751 & 0.00015 & 0.27338 \\ \text { Skewness } & 0.51001 & 2.31367 & -5.31187 \\ \text { (Sk=0) } & & & \\ \text { Kurtosis } & -0.01994 & 17.85503 & 52.87873 \\ \text { (Ku=0) } & 26.144 & 8556.208 & 73234.33 \\ \text { JB } & (0.00000) & (0.00000) & (0.00000) \\ & 1437.357 & 952.2366 & 625.8777 \\ \text { Q(5) } & (0.00000) & (0.00000) & (0.00000)\end{array}$

\subsection{Linear and Rolling Regressions}

To check the expected negative pattern between trading volumes and transactions costs, we first estimated an OLS (Ordinary Least Squares) model not reported here to save space. The results 
show a very marked effect of transaction costs on trading volumes (-1.27). However, diagnostic tests reveal some autocorrelation (Durbin Watson and Breush-Godfrey LM tests were performed and are available on request) and the ARCH test is indicative of conditional heteroskedasticity.

To improve our seminal regression, we first estimate an ARIMA (AutoRegressive Integrated Moving Average) model with $\mathrm{AR}(1)$ and $\mathrm{AR}(5)$ terms. The choice of the optimal lag length is based on the correlograms (see appendix for details) and on AIC information criterion. The ARIMA estimates reveal that the effect of transaction costs on trading volumes is now similar to the values reported in previous studies: -0.38 . This elasticity is very similar to Bismans and Damette (2008) who used intraday data for two days in November 2004 and it is slightly higher than the elasticity obtained by Schmidt (2008). That is, a plausible $100 \%$ increase in transaction costs from the introduction of a Tobin tax would slash the Forex trading volume by $38 \%$.

Though previous ARIMA estimates are more reliable than OLS estimates, they do not explicitly model conditional heteroskedasticity (Engle (1982) and Bollerslev (1986)). It is now well known that conditional heteroskedasticity is a common issue in financial time series models. The $\mathrm{ARCH}$ test we performed attests to the occurrence of this phenomenon. We therefore try to improve previous linear estimates by using ARCH and GARCH models. Finally, we have a preference for a Garch $(1,1)$ model in line with the study of Hansen and Lunde (2005) who find that GARCH $(1,1)$ is not outperformed by more sophisticated models when they study exchange rate data properties. GARCH estimates provide a lower elasticity (-0.27) than in ARIMA estimates and previous studies. The slight discrepancy between this value and values in previous studies may arise because we now take account of conditional heteroskedasticity. In addition, we use more recent data than previous studies and so capture the highly unstable episodes of the period 2008-2010. A further/An alternative explanation may be the definition of transaction costs used in this paper whereas previous studies only proxy transactions costs by absolute spreads.

Finally, the robustness of our single equation estimations needs to be checked by a simultaneous equations model regression. The results from Table 2 ignore the probable endogeneity of transactions costs: transactions costs are both a determinant of the trading volume and a function of the trading volume (see for instance Demos and Goodhart [1996] and Hartmann $[1998,1999])$. To address this issue, we estimate the following simultaneous dynamic equations model as in Damette (2013):

$$
\begin{aligned}
\ln (\text { volume })_{t} & =\beta_{1, X_{t}}+\beta_{2, X_{t}}\left(X_{t}\right) \ln (T C)_{t}+\beta_{3, X_{t}} \ln (\text { volume })_{t-k}+\beta_{4, X_{t}} \ln (\text { volatility })_{t}+\varepsilon_{1, t, X_{t}} \\
\ln (T C)_{t} & =\beta_{5, X_{t}}+\beta_{6, X_{t}} \ln (\text { volume })_{t}+\beta_{7, X_{t}} \ln (\text { spread })_{t-k}+\beta_{8, X_{t}} \ln (\text { volatility })_{t}+\varepsilon_{2, t, X_{t}}
\end{aligned}
$$


The first equation is our equation of interest and is similar to equation (1) previously estimated; it captures the elasticity of trading volumes with respect to transaction costs, whereas the second equation focuses on the effect of trading volumes on transaction costs. Since we assume a non-zero correlation between errors, a 3SLS (Three-Stage Least Squares) estimator is better than the individual equation methods (2SLS, LIML, etc.) if the model is correctly specified. Indeed, the 3SLS can cater for cross-correlation between error terms.

Once again, the lag choice is based on the correlograms, the AIC but also on RSquared and RMSE (Root Mean Squared Errors) indicators. Our 3SLS estimates are outlined in table 3. The 3SLS estimates lead to very similar results to GARCH estimates: the currency transaction tax elasticity is now -0.24 .

Table 2: ARIMA and GARCH estimations

tab:addlabel

$\begin{array}{rrrrr} & \text { Coefficient } & \text { z-stat } & \text { Coefficient } & \text { z-stat } \\ \text { Intercept } & 9.16 & 17.97 & 9.79 & 22.37 \\ \text { Transaction Costs } & -0.38 & -7.18 & -0.27 & -5.93 \\ \text { Volatility } & 0.18 & 12.46 & 0.21 & 16.43 \\ \text { Volume(-1) } & 0.63 & 29.11 & 0.65 & 25.81 \\ \text { Volume(-5) } & 0.28 & 11.52 & 0.34 & 14.96 \\ \text { LogLikelihood } & 222.60 & & 234.16 & \\ \text { Wald } & 2437.08(0.00) & & 5438.05(0.00) & \\ \text { Observations } & 594 & & 594 & \end{array}$

Table 3: 3SLS results

\begin{tabular}{rrrrrr} 
Equation 1 & Coefficient & Z-stat & Equation 2 & Coefficient & z-stat \\
Intercept & -0.82 & -1.48 & Intercept & -0.92 & -3.37 \\
Transaction Costs & -0.24 & -3.48 & Volume & -0.03 & -1.74 \\
Volatility & 0.09 & 5.36 & Volatility & 0.03 & 3.07 \\
Volume(-1) & 0.59 & 18.09 & Transaction Costs (-1) & 0.30 & 7.31 \\
Volume(-5) & 0.29 & 8.91 & Transaction Costs (-2) & 0.17 & 3.99 \\
& & & Transaction Costs (-3) & 0.07 & 1.70 \\
& & & Transaction Costs (-4) & 0.07 & 1.66 \\
RMSE & \multirow{2}{*}{0.16} & & Transaction Costs (-5) & 0.26 & 6.26 \\
Rsquared & 0.76 & RMSE & 0.09 & \\
& & & Rsquared & 0.71 &
\end{tabular}

Finally, since we expect some instability in the dynamics of the elasticity, we perform a rolling regression to test this intuition simply. The following figure shows the coefficients of 

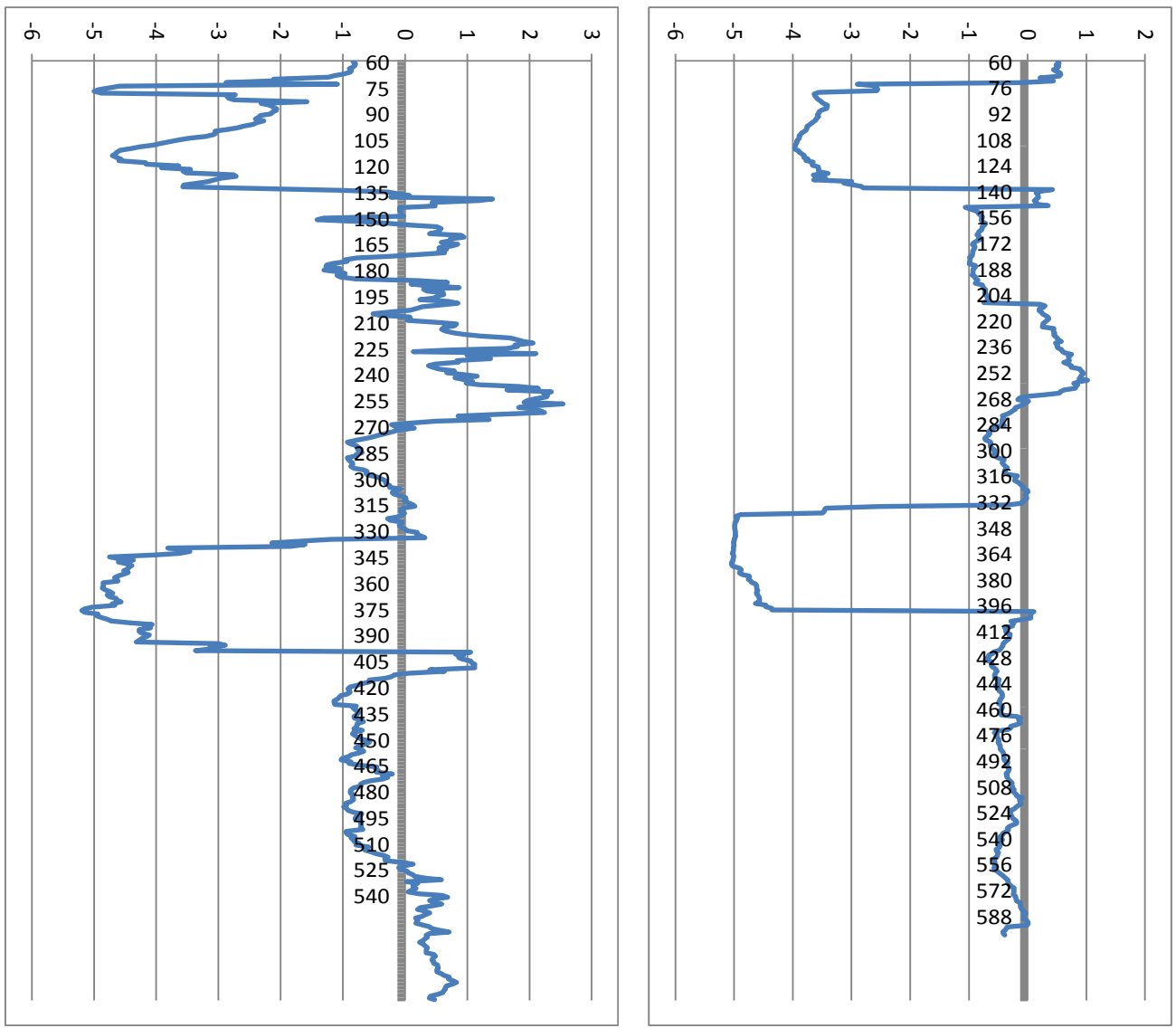

0
0
0
0
0
0
0
0
0
0
0
0
0
0
0
0
0
0
0 
regressions of changes in trading volumes estimated over rolling windows of 60 business days on the basis of the single and the simultaneous equations system respectively. ${ }^{3}$ (we also performed the same rolling regression with 20 business days to check the robustness of these results). The following charts show the rolling dynamics of trading volume elasticity. They suggest that the relationship between trading volume and volatility is somewhat instable and regime-dependent; indeed, elasticity seems to differ in times of stress and times of quiet. Interestingly, rolling regressions related to both single and system estimations are highly convergent. In the same vein as Galati (2000), this may mean that in stressful times very high volatility may induce traders to withdraw from the Forex. This leads to a strong negative correlation between trading volumes and transaction costs. In the remainder of the paper, we investigate in more details this regime dependent and more precisely nonlinear relationship using Markov-Switching models.

\section{A Markov Switching Analysis}

\subsection{Methodology}

To deepen the previous analysis, we use a Markov Switching methodology. MS models have been widely used in economics and finance since the seminal work of Hamilton (1989). Shortly afterwards, Cai (1994) and Hamilton and Susmel (1994) utilised this kind of methodology to capture highly volatile financial regimes? Generally, in MS models, econometricians distinguish two or more regimes that are the outcome of a Markov chain whose realizations are unobserved. MS modelling is a major tool with which to better interpret Forex conditions by inferring the latent state of the market and of the economy.

Let $T>0$ be a fixed maturity time and denote by $\left(X_{t}\right)_{t \leq s \leq T}$ a homogenous continuous time Markov chain on finite state space $\mathcal{S}:=\{1,2, \ldots, N\}$. It can be viewed as an observable exogenous quantity as an economic factor. We assume that the time invariant matrix $Q$ denotes the infinitesimal generator $\left(q_{i j}\right)_{i, j=1, \ldots, m}$ of $X$, where $q_{i j}$ is an infinitesimal intensity of $X$. This generator is defined as $q_{i j} \geq 0$, for all $i \neq j \in \mathcal{S}$ and $q_{i i}=-\sum_{j \neq i ; j \in \mathcal{S}} q_{i j}<0$ for all $i \in \mathcal{S}$.

We consider a general regime switching model given by

$\ln (\text { volume })_{t}=\beta_{1, X_{t}}+\beta_{2, X_{t}}\left(X_{t}\right) \ln (T C)_{t}+\beta_{3, X_{t}} \ln (\text { volume })_{t-k}+\beta_{4, X_{t}} \ln (\text { volatility })_{t}+\varepsilon_{t, X_{t}}$

where $\varepsilon_{t, X_{t}}$ follows the distribution given by $\varepsilon_{t, X_{t}} \sim \mathcal{N}\left(0, \sigma_{X_{t}}^{2}\right)$.

Moreover, for all $i=\{1,2, \ldots, 4\}, \beta_{k}\left(X_{t}\right)$ are parameters whose values depend on the state of the Markov chain $X$ at time $t \in[0, T]$. In fact, we have $\beta_{i, X_{t}}:=\left\langle\beta, X_{t}\right\rangle$ where $\langle$,$\rangle denotes the$

\footnotetext{
${ }^{3}$ We choose 60 business days in line with Galati (2000).
} 
standard scalar product in $\mathbb{R}^{N}, \beta:=\left(\beta_{1}, \beta_{2}, \ldots, \beta_{N}\right) \in \mathbb{R}^{N}$ and $X_{t}=e_{j}$ with $e_{j}$ a vector of the canonical basis of $R^{N}$ (i.e. $e_{j}:=(0, \ldots, 0,1,0 \ldots, 0)$ ).

Only single equation results are economically and statistically consistent. Thus, we report only the single equation estimates. In order to check the robustness of our model, the three following specifications are tested:

\section{Model A:}

$$
\log (\text { volume })_{t}=\beta_{1}+\beta_{2, X_{t}} \log (T C)_{t}+\beta_{3} \log (\text { volume })_{t-5}+\beta_{4} \log (\text { volatility })_{t}+\varepsilon_{t, X_{t}} .
$$

\section{Model B:}

$$
\log (\text { volume })_{t}=\beta_{1, X_{t}}+\beta_{2, X_{t}} \log (T C)_{t}+\beta_{3} \log (\text { volume })_{t-1}+\beta_{4, X_{t}} \log (\text { volatility })_{t}+\varepsilon_{t, X_{t}} .
$$

\section{Model C:}

$$
\log (\text { volume })_{t}=\beta_{1, X_{t}}+\beta_{2, X_{t}} \log (T C)_{t}+\beta_{3} \log (\text { volume })_{t-5}+\beta_{4} \log (\text { volatility })_{t}+\varepsilon_{t, X_{t}} \text {. }
$$

\subsection{Results}

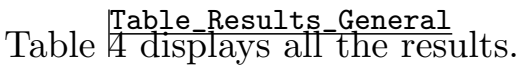

Three different regimes of exchange rate volatility can be considered by the Markov Switching model: high (probabilities close to 1), intermediate (probabilities mid-way between 1 and 0 ) and low (probalities close to 0) exchange rate volatility regimes. Models A and B are consistent econometrically. Anyway, models A and B capture two quite distinct regimes: a low variance regime (0.028 and 0.014 respectively) and a very high variance regime (0.059 and 0.039 respectively). In both models, currency transaction tax elasticity $\left(\beta_{2}\right)$ is lower in the low variance regime -0.17 versus -0.21 for model $\mathrm{A}$ and -0.34 versus -0.62 for model $\mathrm{B}$. Whichever the model and the specification (A or B) considered, the low variance regime lasts longer than the other regime. Hence, the high volatility regime seems to be consistent with a market stress or a crisis period. In contrast, the low variance regime is probably related to a "normal" period; there a no particular announcements or news that intensify exchange rate volatility. In other words, a plausible increase of $100 \%$ of the transaction costs from the introduction of a Tobin tax would lead to a reduction of $34 \%$ ( $62 \%$ for model B) of the Forex trading volume in normal times (these values are very similar to values from previous linear regression studies) but of only $17 \%$ ( $34 \%$ for model B) in turbulent times. Finally, the $\beta_{4}$ coefficient is positive in model $\mathrm{A}$ and in the high variance regime in model B. This attests to the presence of the Mixture Distribution 


\begin{tabular}{|c|c|c|c|c|}
\hline Model & $\mathbf{X}_{\mathrm{t}}$ & $\mathbf{A}$ & $\mathbf{B}$ & $\mathrm{C}$ \\
\hline Lag Volume & & 5 & 1 & 5 \\
\hline $\log \mathrm{L}$ & & 112.7991 & 177.3563 & 64.3542 \\
\hline $\mathrm{AIC}$ & & -207.5982 & -332.7126 & -108.7083 \\
\hline $\mathrm{BIC}$ & & -168.1924 & -284.5499 & -64.9241 \\
\hline \multicolumn{5}{|l|}{ Parameters } \\
\hline \multirow[t]{2}{*}{$\bar{\beta} \beta_{1}$} & 1 & $5.3582(0.5254(0.00))$ & $0.4607(0.6155(0.45))$ & $11.1373(3.7319(0.00))$ \\
\hline & 2 & & $-2.1230(0.9980(0.03))$ & $-2.4835(0.5698(0.00))$ \\
\hline \multirow[t]{2}{*}{$\beta_{2}$} & 1 & $-0.1746(0.0581(0.00))$ & $-0.3391(0.0693(0.00))$ & $0.6952(0.3890(0.07))$ \\
\hline & 2 & $-0.2102(0.0572(0.00))$ & $-0.6163(0.1053(0.00))$ & $-0.7073(0.0655(0.00))$ \\
\hline \multirow[t]{2}{*}{$\beta_{3}$} & 1 & $0.4332(0.0320(0.00))$ & $0.7061(0.0268(0.00))$ & $0.6543(0.0293(0.00))$ \\
\hline & 2 & & & \\
\hline \multirow[t]{2}{*}{$\beta_{4}$} & 1 & $0.1017(0.0200(0.00))$ & $0.1109(0.0208(0.00))$ & $0.1876(0.0182(0.00))$ \\
\hline & 2 & & $-0.0759(0.0509(0.14))$ & \\
\hline \multirow[t]{2}{*}{$\sigma$} & 1 & $0.058692(0.0061(0.00))$ & $0.039482(0.0024(0.00))$ & $0.163031(0.0405(0.00))$ \\
\hline & 2 & $0.028105(0.0004(0.00))$ & $0.013669(0.0020(0.00))$ & $0.039013(0.0022(0.00))$ \\
\hline \multirow[t]{2}{*}{$Q$} & $q_{11}$ & 0.89 & 1 & 1 \\
\hline & $q_{22}$ & 1 & 0.94 & 1 \\
\hline
\end{tabular}

Table 4: Switching Markov estimates for different models. In parenthesis: Std and p.values.

Hypothesis $(\mathrm{MDH})$ on the Forex market. Moreover, the results of model B reinforce the result of Damette (2013) that the volatility/volume relationship seems to be more clear-cut in high variance regimes.

\subsection{Diagnostic tests}

In this section, we conduct diagnostic tests to discriminate between models A and B.

\subsubsection{Good Classification Measures}

An ideal model is one that classifies regimes sharply and has smoothed probabilities which are either close to zero or one. In order to measure the quality of regime classification, we propose two measures: 
(1) The regime classification measure (RCM) introduced by Ang and Bekaert (2002) and generalized for multiple states by Baele (2005). Good regime classification is associated with low RCM statistic value: a value of 0 means perfect regime classification and a value of 100 implies that no information about regimes is revealed.

(2) The smoothed probability indicator introduced by Goutte and Zou (2013). A good classification for data can be also seen when the smoothed probability is less than 0.1 or greater than 0.9 . This then means that the data at time $t \in[0, T]$ is, with a probability exceeding $90 \%$, in one of the regimes for the $10 \%$ error.

In the following, we evaluate the RCM statistics and the smoothed probability indicators for all models. The results are stated in Table $\frac{T}{5}$.

Table 5: RCM statistics and percentage given by the smoothed probability indicator for $10 \%$.

$\begin{array}{ccc}\text { Model } & \text { RCM } & \text { Perc }^{10 \%} \\ \text { A } & 8.32 & 91.34 \% \\ \text { B } & 19.44 & 81.66 \% \\ \text { C } & 7.00 & 92.19 \%\end{array}$

TableRCM

Table 5 clearly documents that for all models the regime classification measure (RCM) is close to zero and the smoothed probability indicator is in most cases close to $90 \%$. This result indicates that the two regime states obtained via the Markov Switching estimation procedure classify the data very effectively. As a consequence, the Markov Switching methodology is an appropriate method for evaluating the dynamics of the Forex trading volume.

Let us now discriminate among models A, B and C. Firstly, the model with the best fit is the one yielding the highest log likelihood value. The higher the value the better the fit of the data. However, we have to weight these values with those given by the (RCM) reported in Table 5, which measures the good classification of the data. Even if a model has a log likelihood value, its RCM needs to be close to zero.

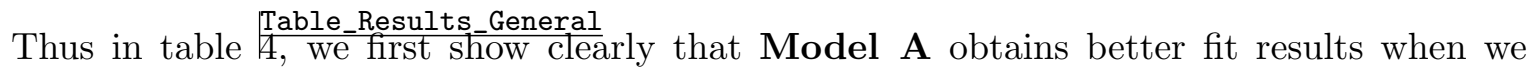
take a parameter $\beta_{2}$ regime switching dependent variable with a non regime switching intercept. LOGL, AIC and BIC criteria are all better for Model A than Model C. Secondly, the RCM

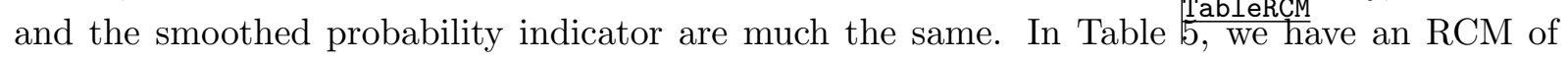
8.32 for Model A versus 7.00 for Model C, and both classify more $91 \%$ of the data well. So Model A looks to be a better choice than Model C.

We find evidence that the LOGL of Model B is higher than that of Model A: 177.3563 versus 112.7991. It therefore looks a better choice. Nevertheless, Model $\mathbf{C}$ has an RCM of 
19.44 and Model A 8.32. For the smoothed probability indicator, Model A obtains a value of $91.34 \%$ but Model C only $81.66 \%$.

In conclusion, for all the diagnostic results, model Model A seems to provide the best fit for the data and a good classification of the data with significant regime periods.
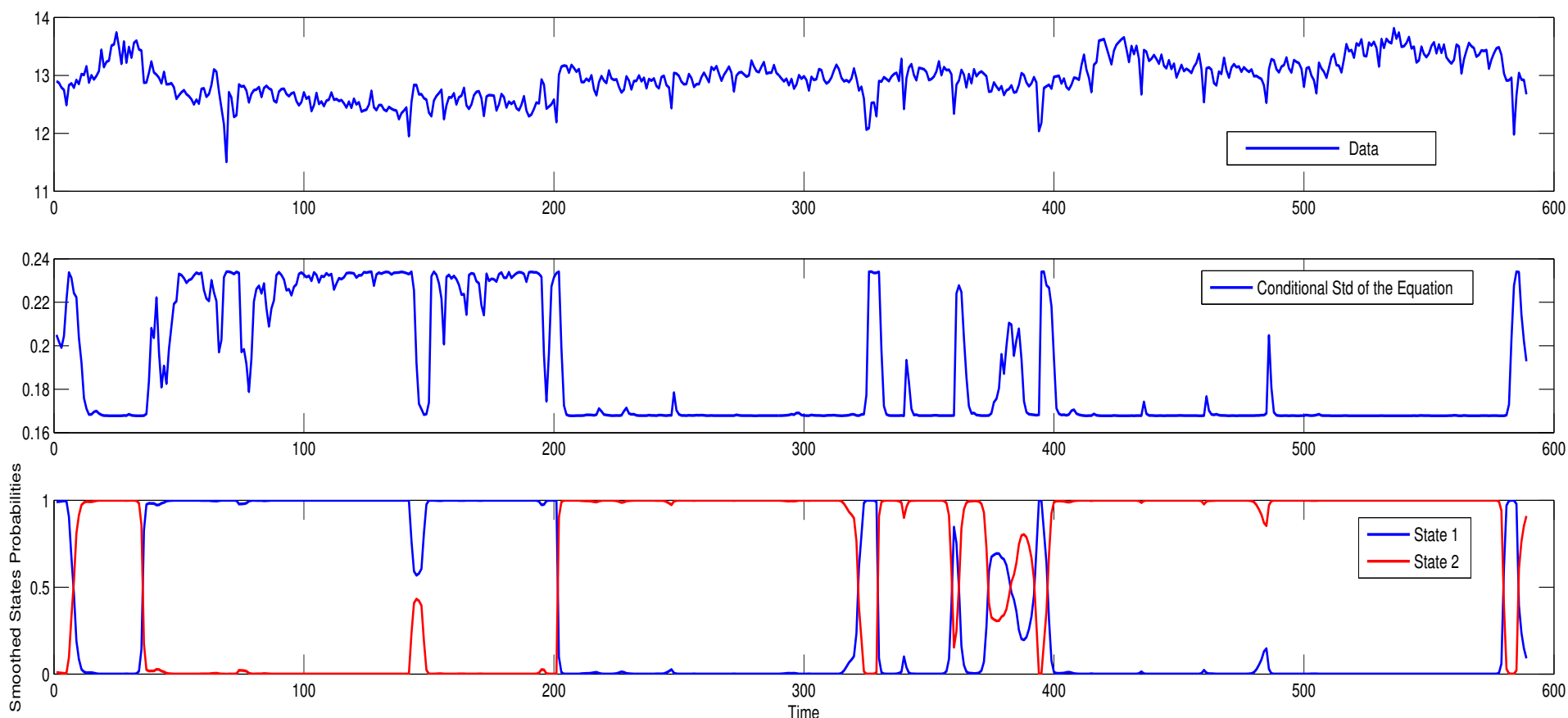

Figure 4: First graph shows our data. The second shows the conditional standard deviation of model

A. The third shows the smoothed probabilities obtained with Model A. 


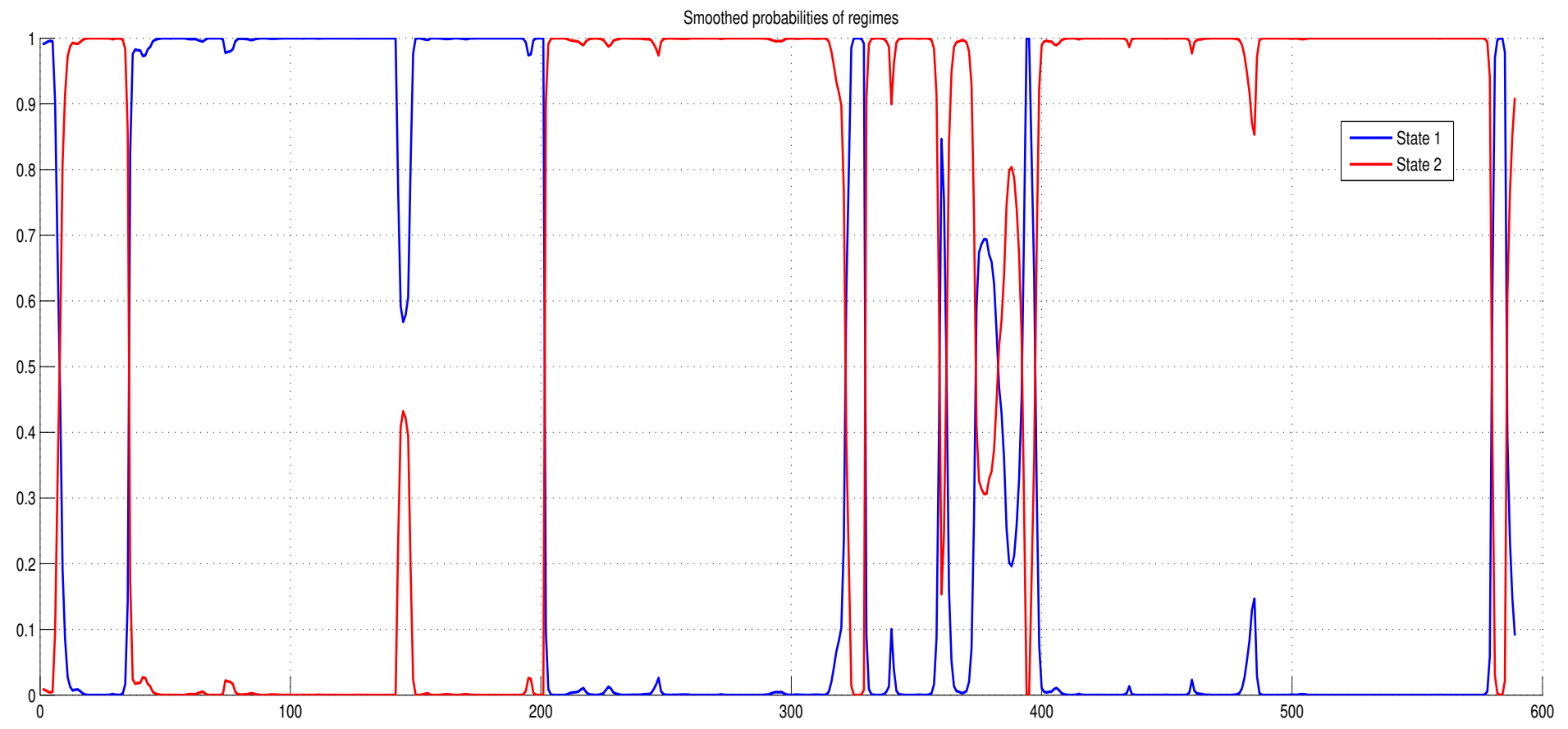

PlotResults2 Figure 5: Graphs of the smoothed probabilities obtained with Model A in the case of two regime states. 


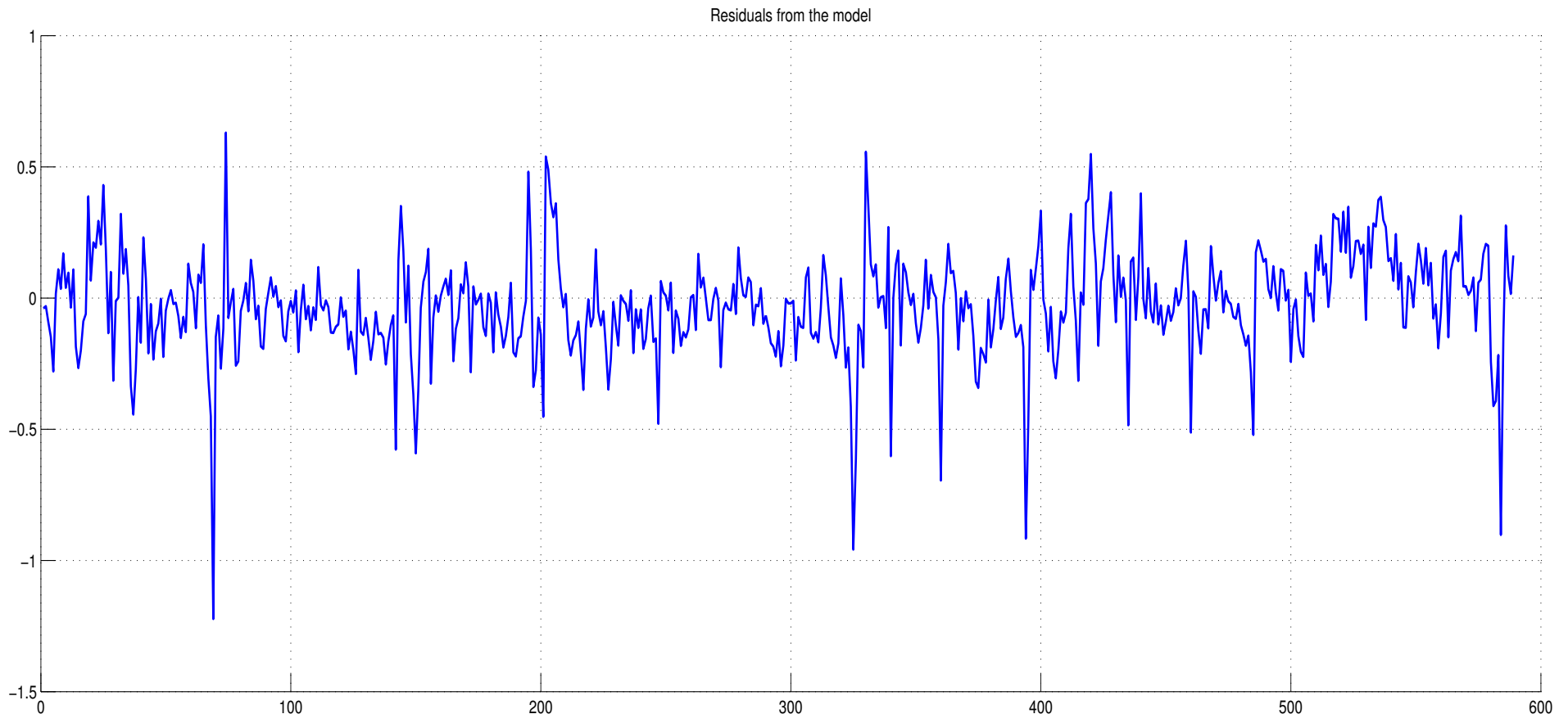

PlotResults3

Figure 6: Graphs of the residuals obtained with Model A in the case of two regime states. 


\subsubsection{Test of the equality of the variance in each regime state}

We perform a Fisher test of the hypothesis that the variance of noise in each regime differs. The calculated value $F=2.0883$ has to be compared with the tabulated value $f(500,500,0.05)=$ 1.16. Since $F>1.16$, we can reject the null hypothesis of equal variance $\sigma_{1}$ and $\sigma_{2}$ in each regime state at a $95 \%$ level of significance.

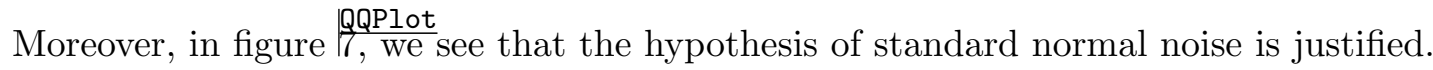

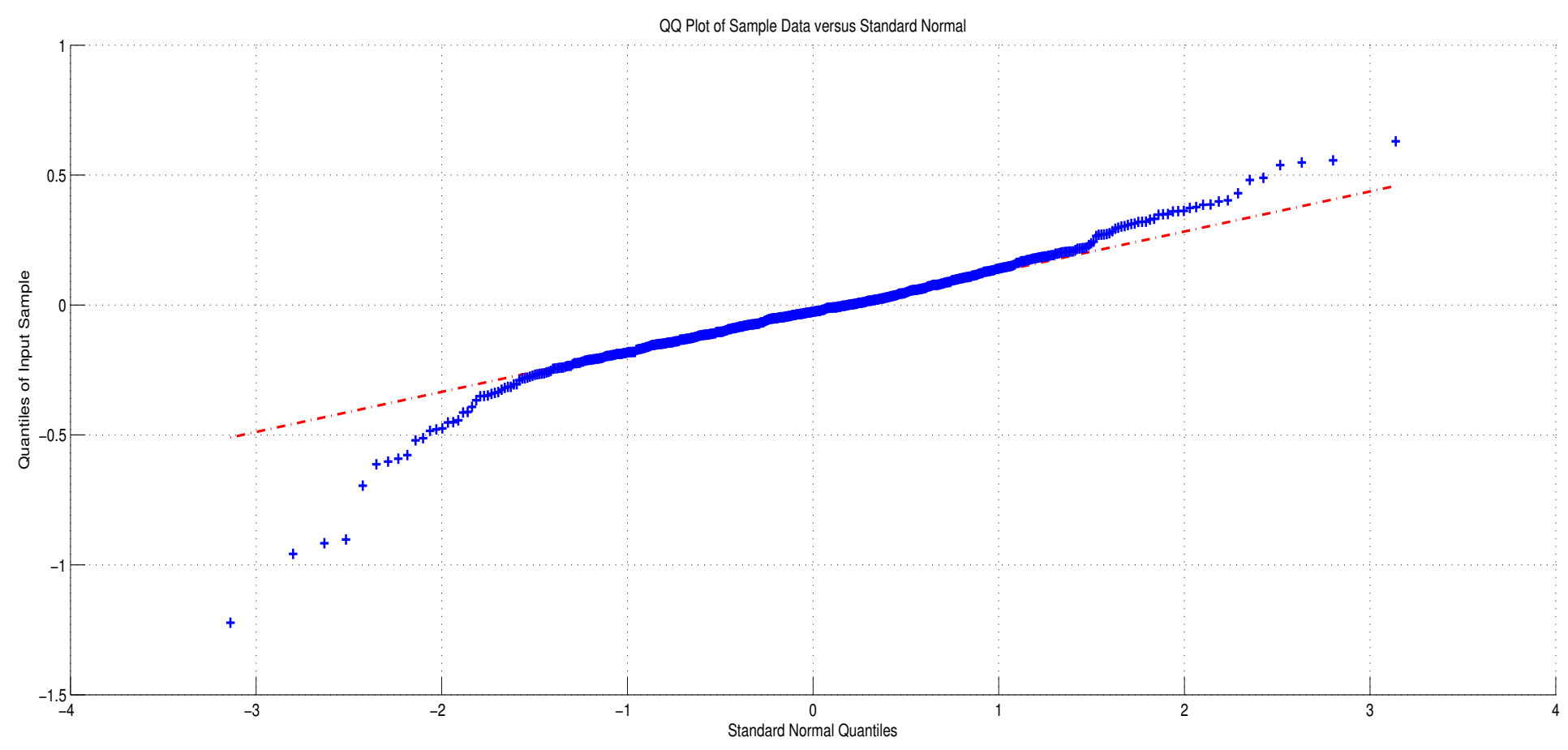

Figure 7: Plots 


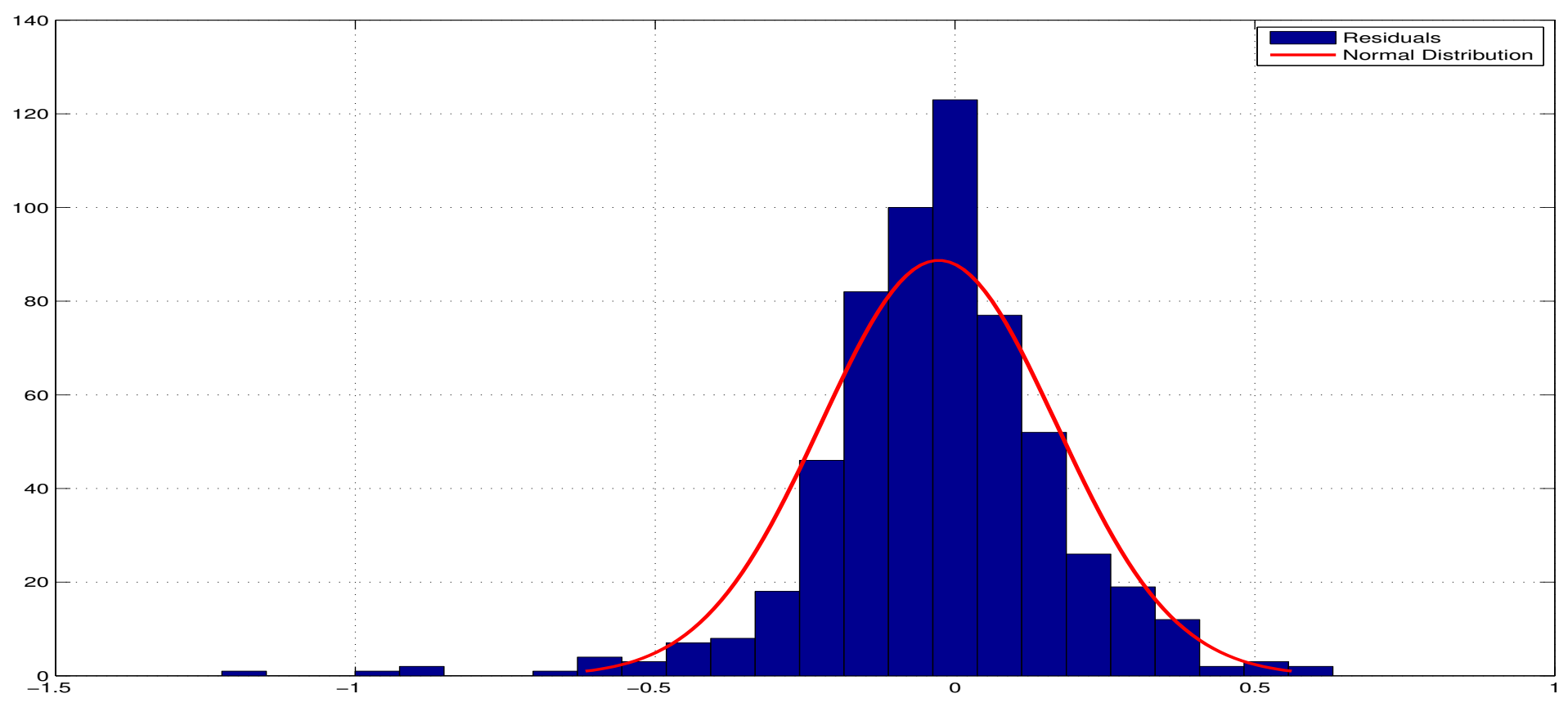

Figure 8: Graph of the empirical distribution of the residuals of our model against a normal distribution.

\subsubsection{Tests of the nullity hypothesis of each regime switching parameter}

Wald statistics have been computed to test the null hypothesis of nullity of the parameters $\beta_{i}$, $i=1, \ldots, 4$. This is the statistical test $\mathcal{H}_{0}: \quad \beta_{i}=0$ against $\mathcal{H}_{1}: \beta_{i} \neq 0$. The results are given in the following table $\frac{T}{6}$.

By comparing these results with a $\chi^{2}$ distribution, we can see that the computed values are higher than the tabulated values as $\chi^{2}(1,0.05)=3.84$ or even $\chi^{2}(1,0.01)=6.64$. Thus we reject the null hypothesis $\mathcal{H}_{0}$ for all parameters (regime switching parameters or not) $\beta_{i}$ for $i \in\{1,2,3,4\}$. 
Table 6: Wald Statistics

\begin{tabular}{ccc} 
& \multicolumn{2}{c}{ Regime switching parameter } \\
Parameter & State 1 & State 2 \\
Transaction cost: $\beta_{2}$ & 9.0268 & 13.5047
\end{tabular}

Non regime switching parameters

Parameters

Intercept: $\beta_{1}$

Lag Volume: $\beta_{3}$

Volatility: $\beta_{4}$
182.8512

25.9513

\section{Conclusions and policy discussion}

We now finally discuss our results. Considering the Markov Switching estimates, trading was historically less sensitive to transaction costs from the end of October 2008 to June 2009 and, to a lesser extent, to spring 2010 than in the rest of the sample. The first period was that of the post Lehman Brothers failure and "Black October "whereas the second saw the European sovereign debt crisis and a large depreciation in the Euro. Overall, the nonlinear methodology ${ }^{4}$ used in this paper point to two distinct regimes: negative and relatively strong elasticity during "normal times" and a weakly negative elasticity during periods of market adjustment. Overall, traders seem to be less sensitive to transaction costs during the period immediately following a turbulent episode than during normal periods. As a consequence, a Tobin tax might always reduce the trading volume and the market depth but the decline in the number of transactions would be less pronounced in periods of adjustment than in normal times.

How are we to interpret this result? It is well known that there is a continuum of heterogeneous traders entering the Forex market: informed traders, fundamentalists but also chartists, speculators and noise traders. As a consequence, we need to evaluate the elasticity dynamics or the sensitivity of the trading activity to transaction costs over time by considering this heterogeneity. In this way, our results may be related to the heterogeneous agents models literature developed by Frankel and Froot (1988) and extended by De Grauwe and Grimaldi (2005) among others. In this kind of model, the authors allow for the presence of both chartists and fundamentalists in the Forex.

\footnotetext{
${ }^{4}$ We also estimate a Smooth Threshold Regression (STR) model to check the robustness of our Markov results. Considering the STR estimates (results are available upon request), traders were less or irrationally sensitive to transaction costs from September 2008 to April 2009 but are very sensitive (strong negative elasticity to transactions costs) in the other periods.
} 
Vigfusson (1997), Bessec and Robineau (2003), Ahrens and Reitz (2005) and more recently De Jong et al (2010) provided empirical evidence of a behavioural heterogeneity in the Forex using Markov Switching Models. They outlined the existence of switching beliefs (chartists, fundamentalists, noise traders) between periods of high and low variances. For instance, Vigfusson (1997) showed that the Forex may be characterised by two different regimes: a chartist regime in which the traders base the forecast on the past behaviour of the exchange rate and a fundamentalist regime based on fundamental economic expectations. The chartist regime has a lower variance and is more persistent than the fundamentalist regime which exhibits greater volatility. In the fundamentalist regime, volatility would therefore seem to be temporary but necessary for the price adjustment.

Since our nonlinear estimates exhibit two distinct regimes (low and high variance) with two slightly different currency transaction tax elasticities (-0.21 and -0.17 respectively), we may suggest that the low-variance regime might be the fundamentalist regime and the high-variance regime (lower Tobin tax elasticity) might be the chartist regime. Historically, in the period between October 2008 and April 2009 (high variance regime), fundamentalists seemingly dominated the Forex and set about adjusting the exchange rate to its fundamentals. Risk decreased during this period and then the volume fell below September 2008 levels with the hot potato phenomenon being less predominant(see also Melvin and Taylor (2009). Thus, fundamentalists prevailed over chartists in the Forex during this highly volatile period. This may suggest that fundamentalists are less sensitive to transaction costs than chartists. Hence, a Tobin tax would impact the trading activity of fundamentalists less than that of the chartists.

This means our results are consistent with Tobin's underlying thinking (1974, 1978, 1996) that a tax would render speculative and destabilizing transactions less profitable than longterm and stabilizing transactions and so would be a useful tool for reducing turbulence on financial markets and exchange rate volatility. Since a tax would penalize chartists more than fundamentalists, it could reduce exchange rate volatility in line with Frankel's model (1996). Accordingly, a Tobin tax would not be an indiscriminate tax as suggested by its opponents since the market would be guided by fundamentalists rather than by chartists. This study is a first step towards understanding which categories of agents dominate the market under the various market regimes and how they would react to the introduction of a tax. More detailed data about the type of trading on the market would be help to improve the results of this study in the future. However, such data is hard to obtain.

Our empirical study is also a good empirical complement to existing studies of the effectiveness of a transaction tax within an agent-based framework. For instance, Demary (2008), updating the model of Frankel (1996), using a model similar to De Grauwe and Grimaldi (2005) explained that transaction taxes are capable of reducing volatility by reducing short-term spec- 
ulation and promoting long-term investment. In addition, our paper enhances the findings of Damette (2013). He outlined that the relationship between volatility and trading volume would be stronger in unstable periods, like the period between September 2008 and April 2009 and that a tax would sharply reduce exchange rate volatility in such periods. We suggest that the high volatility encountered in periods of this kind might be a good volatility, that is, volatility ensuring the necessary adjustment of the exchange rate to the equilibrium price and of the aggregate volatility to the equilibrium value thanks to the fundamentaliststs work. Volatility would therefore be greater over this period because the information content of transactions on the part of fundamentalists would be higher (hence a stronger MDH). A high Tobin tax might thus be counterproductive at such times: by reducing the trading volume of fundamentalists, the tax would lower the information content of trading volume and delay the market adjustment process.

Finally, our results prompt certain policy recommendations. If a Spahn-style tax were introduced, caution would be called for in adjusting tax rates. It is important to raise the tax rate during periods when speculative bubbles form and transaction volumes surge (as in September 2008) but to lower them quickly during the market adjustment period so fundamentalists are not penalised during this phase. The taxation rate should therefore be raised ahead of the formation of any speculative dynamics, but it is difficult in practice to correctly spot this point in time.

\section{Appendix}




\begin{tabular}{|c|c|c|c|c|c|c|}
\hline Autocorrelation & Partial Correlation & & $A C$ & PAC & Q-Stat & Prob \\
\hline . & . $\left.\right|^{* \star \star}$ & 1 & 0.519 & 0.519 & 162.50 & 0.000 \\
\hline.$f^{* * *}$ &.$f^{*}$ & 2 & 0.393 & 0.169 & 255.60 & 0.000 \\
\hline$f^{\star \star \star}$ &. . $^{*}$ & 3 & 0.358 & 0.143 & 333.20 & 0.000 \\
\hline$f^{\star \star * *}$ & $.1^{*}$ & 4 & 0.406 & 0.207 & 433.08 & 0.000 \\
\hline..$^{* * * *}$ & $.1^{* * \star}$ & 5 & 0.564 & 0.375 & 625.88 & 0.000 \\
\hline.$f^{* \star *}$ & & 6 & 0.366 & -0.102 & 707.51 & 0.000 \\
\hline.$j^{* *}$ & . & 7 & 0.321 & 0.025 & 770.42 & 0.000 \\
\hline $.1^{* *}$ &. & 8 & 0.299 & 0.015 & 824.85 & 0.000 \\
\hline $.1^{* *}$ & . & 9 & 0.303 & -0.009 & 881.11 & 0.000 \\
\hline $.1^{* *}$ & *|. & 10 & 0.284 & -0.112 & 930.51 & 0.000 \\
\hline $.1^{* *}$ &..$^{*}$ & 11 & 0.306 & 0.153 & 987.94 & 0.000 \\
\hline $.1^{* *}$ & .1. & 12 & 0.270 & -0.007 & 1032.7 & 0.000 \\
\hline $.1^{* *}$ & . & 13 & 0.253 & 0.013 & 1072.1 & 0.000 \\
\hline..$^{* *}$ & . & 14 & 0.255 & 0.043 & 1112.2 & 0.000 \\
\hline..$^{* *}$ & 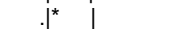 & 15 & 0.269 & 0.116 & 1156.9 & 0.000 \\
\hline..$^{* *}$ & .1. & 16 & 0.276 & -0.036 & 1203.9 & 0.000 \\
\hline..$^{* *}$ & .1. & 17 & 0.231 & -0.002 & 1236.9 & 0.000 \\
\hline $.1^{* *}$ & . & 18 & 0.215 & 0.002 & 1265.4 & 0.000 \\
\hline $.1^{* *}$ & . & 19 & 0.222 & 0.011 & 1296.1 & 0.000 \\
\hline..$^{* *}$ &. & 20 & 0.244 & -0.009 & 1333.3 & 0.000 \\
\hline $.1^{\star *}$ & . & 21 & 0.236 & 0.043 & 1367.9 & 0.000 \\
\hline. . $^{*}$ &. & 22 & 0.209 & 0.001 & 1395.1 & 0.000 \\
\hline.$\left.\right|^{*}$ &. & 23 & 0.188 & -0.009 & 1417.3 & 0.000 \\
\hline.$\left.\right|^{*}$ & . & 24 & 0.196 & 0.013 & 1441.3 & 0.000 \\
\hline.$\left.\right|^{*}$ &. & 25 & 0.198 & 0.011 & 1466.0 & 0.000 \\
\hline.$\left.\right|^{*}$ &. & 26 & 0.198 & -0.003 & 1490.7 & 0.000 \\
\hline.$\left.\right|^{*}$ & . & 27 & 0.178 & -0.010 & 1510.7 & 0.000 \\
\hline.$\left.\right|^{*}$ & .1. & 28 & 0.163 & 0.003 & 1527.4 & 0.000 \\
\hline.$\left.\right|^{*}$ & . & 29 & 0.185 & 0.037 & 1549.0 & 0.000 \\
\hline.$\left.\right|^{*}$ &. & 30 & 0.180 & 0.005 & 1569.6 & 0.000 \\
\hline.$\left.\right|^{*}$ & .1. & 31 & 0.208 & 0.065 & 1597.1 & 0.000 \\
\hline.$\left.\right|^{*}$ & . & 32 & 0.176 & -0.007 & 1616.9 & 0.000 \\
\hline.$\left.\right|^{*}$ &. & 33 & 0.158 & -0.007 & 1632.8 & 0.000 \\
\hline.$\left.\right|^{*}$ & . & 34 & 0.161 & -0.014 & 1649.3 & 0.000 \\
\hline.$\left.\right|^{*}$ & . & 35 & 0.168 & 0.017 & 1667.3 & 0.000 \\
\hline.$\left.\right|^{*}$ & . & 36 & 0.178 & -0.024 & 1687.6 & 0.000 \\
\hline
\end{tabular}




\begin{tabular}{|c|c|c|c|c|c|c|}
\hline Autocorrelation & Partial Correlation & & $A C$ & PAC & Q-Stat & Prob \\
\hline..$^{\star \star \star \star \star *}$ &..$^{* \star * \star}$ & 1 & 0.700 & 0.700 & 295.77 & 0.000 \\
\hline.$f^{* \star \star * *}$ & $.1^{* *}$ & 2 & 0.638 & 0.289 & 541.49 & 0.000 \\
\hline.$\left.\right|^{\star \star \star \star \star}$ &..$^{* *}$ & 3 & 0.621 & 0.215 & 774.45 & 0.000 \\
\hline.$f^{\star \star \star \star \star \star}$ & $.1^{* *}$ & 4 & 0.645 & 0.243 & 1026.9 & 0.000 \\
\hline$f^{* * * * *}$ &..$^{\star \star * *}$ & 5 & 0.723 & 0.359 & 1344.3 & 0.000 \\
\hline..$^{* * * *}$ & & 6 & 0.620 & -0.036 & 1578.4 & 0.000 \\
\hline..$^{\star \star \star \star \star}$ & .1. & 7 & 0.565 & -0.051 & 1773.0 & 0.000 \\
\hline..$^{* * * *}$ &. & 8 & 0.577 & 0.064 & 1976.4 & 0.000 \\
\hline..$^{* \star \star *}$ & $.1^{*}$ & 9 & 0.602 & 0.081 & 2198.1 & 0.000 \\
\hline.$\left.\right|^{\star \star \star \star *}$ & .1 . & 10 & 0.615 & 0.033 & 2429.7 & 0.000 \\
\hline.$\left.\right|^{\star \star \star \star *}$ & .1. & 11 & 0.576 & 0.036 & 2633.0 & 0.000 \\
\hline..$^{\star \star * \star \star}$ &. & 12 & 0.551 & 0.048 & 2819.6 & 0.000 \\
\hline..$^{* \star \star \star}$ &. & 13 & 0.552 & 0.016 & 3007.3 & 0.000 \\
\hline..$^{\star * \star *}$ &. & 14 & 0.565 & 0.019 & 3204.0 & 0.000 \\
\hline..$^{* \star \star \star *}$ &. & 15 & 0.565 & 0.030 & 3401.0 & 0.000 \\
\hline $.1^{\star \star \star \star *}$ & .1. & 16 & 0.549 & 0.033 & 3587.2 & 0.000 \\
\hline.$\left.\right|^{* \star \star \star}$ & .1. & 17 & 0.518 & -0.031 & 3753.3 & 0.000 \\
\hline.$\left.\right|^{* * * *}$ &. & 18 & 0.524 & 0.020 & 3923.7 & 0.000 \\
\hline..$^{* * * *}$ & . & 19 & 0.517 & -0.014 & 4089.8 & 0.000 \\
\hline..$^{* * * *}$ & . & 20 & 0.537 & 0.062 & 4269.4 & 0.000 \\
\hline..$^{* \star \star *}$ & .1. & 21 & 0.512 & -0.015 & 4433.0 & 0.000 \\
\hline $.1^{* \star \star \star *}$ & .1. & 22 & 0.486 & -0.017 & 4580.5 & 0.000 \\
\hline.$f^{\star \star *}$ & .1. & 23 & 0.474 & -0.035 & 4721.1 & 0.000 \\
\hline.$\left.\right|^{* \star \star \star}$ & .1. & 24 & 0.502 & 0.073 & 4878.8 & 0.000 \\
\hline $.1^{* \star \star \star}$ &. & 25 & 0.516 & 0.044 & 5046.3 & 0.000 \\
\hline..$^{* \star \star *}$ & . & 26 & 0.488 & -0.013 & 5196.0 & 0.000 \\
\hline.$\left.\right|^{\star \star \star}$ &. & 27 & 0.468 & 0.007 & 5334.1 & 0.000 \\
\hline$\left.\right|^{\star * \star *}$ &. & 28 & 0.447 & -0.028 & 5460.4 & 0.000 \\
\hline$\left.\right|^{* * *}$ & .1. & 29 & 0.464 & -0.017 & 5596.7 & 0.000 \\
\hline.$^{\star \star \star \star \star}$ & .1. & 30 & 0.490 & 0.046 & 5748.7 & 0.000 \\
\hline.$\left.\right|^{* \star *}$ & . & 31 & 0.442 & -0.050 & 5872.7 & 0.000 \\
\hline.$\left.\right|^{* * *}$ &. & 32 & 0.417 & -0.044 & 5983.5 & 0.000 \\
\hline $.1^{* \star *}$ & ${ }^{*}$. & 33 & 0.386 & -0.078 & 6078.4 & 0.000 \\
\hline.$\left.\right|^{* \star \star}$ & . & 34 & 0.406 & -0.007 & 6183.7 & 0.000 \\
\hline.$\left.\right|^{\star * \star}$ & . & 35 & 0.433 & 0.031 & 6303.3 & 0.000 \\
\hline $.1^{* \star *}$ &. & 36 & 0.381 & -0.064 & 6396.4 & 0.000 \\
\hline
\end{tabular}




\section{References}

[1] AHRENS R., REITZ S. [2005], "Heterogeneous expectations in the foreign exchange market: evidence from daily DM / US dollar exchange rates", Journal of Evolutionary Economics 15 , pp. 65-82.

[2] ALIBER R., CHOWDRHY B., YAN S. [2003], "Some Evidence that a Tax on Foreign Exchange Transactions may Increase Volatility", European Finance Review, 7.

[3] ANG A., BEKAERT G. [2002], "Regime Switching in Interest Rates". Journal of Business and Economic Statistics 20 (2), 163-182.

[4] BAELE L. [2005], "Volatility Spillover Effects in European Equity Markets". Journal of Financial and Quantitative Analysis, Vol. 40, No. 2.

[5] BESSEC M., ROBINEAU F.M. [2003], "Comportements chartistes et fondamentalistes : coexistence ou domination alternative sur le marchï£j des changes ?", Revue Economique, 54, 6, pp. 1213-38.

[6] BAUWENS L., RIME D., SUCARRAT G. [2006], "Exchange rate volatility and the mixture of distribution hypothesis", Empirical Economics, 30, pp. 889-911.

[7] BIANCONi G., GAlla T., MARSILI M., PIN P. [2009], "Effects of Tobin Taxes in Minority Game Markets", Journal of Economic Behavior \& Organization, 70, pp. 231-240.

[8] BISMAnS F., DAMETTE O. [2008], "A Currency Transaction Tax Elasticity: an Econometric Estimation", International Economics, 115, 3, pp. 193-212.

[9] CAI [1994], "A Markov model of switching-regime ARCH", Journal of Business \& Economic Statistics, 12, 309-316.

[10] CARRASCO M. [2002], "Misspecified structural change, threshold, and Markov-switching models", Journal of Econometrics, 109, 239-273.

[11] DAMETTE O. [2013], "Tobin Tax and Volatility: a reassessement", Working Papers of BETA, 2013-07 and SSRN.

[12] DE GRAUWE P., GRIMALDI M. [2005], "Heterogeneity of agents, transaction costs and the exchange rate", Journal of Economic Dynamics and Control, 29, pp. 691-719.

[13] DE JONG E., VERSCHOOR W. F. C., ZWINKELS R. C. J. [2010], "Heterogeneity of agents and exchange rate dynamics: Evidence from the EMS", Journal of International Money and Finance, 29, pp. 1652ï£¡1669. 
[14] DEMARY M. [2008], "Who Does a Currency Transaction Tax Harm More: Short-term Speculators and Long-term Investors", Journal of Economics and Statistics, 228, 2-3, pp. 228-250.

[15] DEMOS A., GOODHART C.A. [1996], 'The interaction between the Frequency of Market Quotations, Spreads and Volatility in the Foreign Exchange Market', Applied Economics, 28 , pp. $377-386$.

[16] EHREnStein G., WESTERHOFF F., STAUfFER D. [2005], 'Tobin Tax and Market Depth', Quantitative Finance, 5(2), pp. 213-218.

[17] FRANKEL J.A. [1996], 'How well do Foreign Exchange markets function might a Tobin tax help ?' in GRUNBERG I., UL HAQ M. et KAUL I. (eds), The Tobin Tax: Coping with Financial Volatility, Oxford University Press, pp. 41-81.

[18] FRANKEL J.A., FROOT K.A. [1988], "Chartists, Fundamentalists and the demand of dollars", Greek Economic Review, 10, 1, pp. 49-102.

[19] GALATI G. [2000], "Trading volumes, volatility and spreads in foreign exchange markets: evidence from emerging market countries", BIS Working Paper, n 93.

[20] GOUTTE S. [2013], "Pricing and hedging in stochastic volatility regime switching models", Journal of Mathematical Finance, forthcoming.

[21] GOUTtE S. , ZOU B. [2013], "Continuous Time Regime-Switching Model Applied to Foreign Exchange Rate", Mathematical Finance letters, forthcoming.

[22] HAMILTON J., SUSMEL R. [1994], "Autoregressive Conditional Heteroskedasticity and Changes in Regime", Journal of Econometrics, 64(1-2), 307-33.

[23] HANKE M., HUBER J., KIRCHLER M., SUTTER M. [2010], "The Economic Consequences of a Tobin Tax: An Experimental Analysis", Journal of Economic Behavior and Organization, 74, 1-2, pp. 58-71.

[24] HANSEN P. R., LUNDE A. [2005], "A Forecast Comparison of Volatility Models: Does anything beat a Garch(1,1)?", Journal of Applied Econometrics, 20, pp. 873-889.

[25] HARTMANN P. [1998a], "Do Reuters Spreads Reflect Currencies Differences in Global Trading Activity?", Journal of International Money and Finance, 17(5), pp. 757-785.

[26] HARTMANN P. [1998b], Currency Competition and Foreign Exchange Markets/the Dollar, the Yen and the Euro, Cambridge University Press. 
[27] HARTMANN P. [1999], "Trading Volumes and Transaction Costs in the Foreign Market Evidence from Daily Dollar-Yen Spot Data", Journal of Banking and Finance, 23(5), pp. 801-824.

[28] JEANNE O., ROSE A. [2002], "Noise Trading and Exchange Rate Regimes", Quarterly Journal of Economics, 117(2), pp. 537-569.

[29] LANNE M., VESALA T. [2010], "The effect of a Transaction Tax on Exchange Rate Volatility", International Journal of Finance and Economics, 15(2), pp. 123-133.

[30] LYONS R. [2001], The Market Microstructure Approach to Exchange Rates, MIT Press, Cambridge.

[31] MANNARO K., MARCHESI M., SETZU A. [2008], "Using an artificial market for assessing the impact of Tobin-like transaction taxes", Journal of Economic Behavior and Organization, 67, pp. 445-462.

[32] MATHESON T. [2011], Taxing Financial Transactions : Issues and Evidence, IMF Working Paper.

[33] McCUllOCH M., PACILlO G. [2011], "The Tobin tax: A Review of the Evidence", International of Development Studies Research Paper, 68, pp. 1-77.

[34] MELVIN M., TAYLOR M.P. [2009], "Crisis and the foreign exchange market", Journal of International Money and Finance, 28, pp. 1317-1330.

[35] MENDE A., MENKHOFF L. [2003], "Tobin tax effects seen from the foreign exchange market's microstructure", International Finance, 6, pp. 227-247.

[36] PARK B.-J. [2010], "Surprising Information, the MDH, and the Relationship between Volatility and Trading Volume", Journal of Financial Markets, 13, pp. 344-366.

[37] PARK B.-J. [2011], "Asymmetric Herding as a Source of Asymmetric Return Volatility", Journal of Banking and Finance, 35, pp. 2657-2665.

[38] PELIZZARI P., WESTERHOFF F. [2009], "Some effects of transaction taxes under different microstructures", Journal of Economic Behavior and Organization, 72, pp. 850-863.

[39] SCHMIDT R. [2008], "The Currency Transaction Tax: Rate and Revenue Estimates", United Nations University Press: Tokyo, New York, London..

[40] SCHMIDT R., BHUNSHAN A. [2011], "The Currency Transactions Tax: Feasability, revenue estimates, and potential use of revenue", Human Development Research Paper, $2011 / 09$. 
[41] SHI K., XU J. [2009], "Entry Cost, the Tobin Tax, and Noise Trading in the Foreign Exchange Market", Canadian Journal of Economics, 42(4), pp. 1501-1526.

[42] SONG F. M., ZHANG J. [2005], "Securities Transaction Tax and Market Volatility", Economic Journal, 115, 506, pp. 1103-1120.

[43] TOBIN J. [1974], The New Economics One Decade Older: The Elliot Janeway Lectures in Honor of Joseph Schumpeter, Princeton University Press, Princeton, NJ.

[44] TOBIN J. [1978], "A proposal for International Monetary Reform", Eastern Economic Journal, 3(3-4), pp. 153-159.

[45] TOBIN J. [1984], "On the Efficiency of The Financial System", Lloyds Bank Review, 153 (juillet), pp. 261-286.

[46] TOBIN J. [1996], "Prologue", in GRUNBERG I., UL HAQ M. et KAUL I. (eds), The Tobin Tax: Coping with Financial Volatility, Oxford University Press, pp. 9-18.

[47] VIGFUSSON R. [1997], "Switching between Chartists and Fundamentalists: a Markov Regime-Switching Approach", International Journal of Financial Economics, 2, p. 291205 .

[48] WESTERHOFF F. [2003], "Heterogeneous Traders and the Tobin Tax", Journal of Evolutionary Economics, vol.13, pp. 53-70. 